\title{
CARAVANAS MIGRANTES: \\ DE RESPUESTAS INSTITUCIONALES DIFERENCIADAS A LA REORIENTACIÓN DE LA POLÍTICA MIGRATORIA
}

\author{
Migrant caravans: from differentiated institutional responses \\ to reorientation of migration policy
}

Luciana Gandini*

\begin{abstract}
Resumen. En 2018 y 2019 tuvieron lugar las caravanas migrantes con el fin de llegar a los Estados Unidos, estrategia migratoria adoptada por personas provenientes principalmente de Centroamérica, caracterizadas por una mayor visibilidad, un menor costo y organizadas mediante redes sociales. Se identifican tres oleadas de caravanas a las que se les respondió con medidas institucionales y categorías burocrático-administrativas distintas. Con ello el artículo exhibe los retos de la gobernanza de los flujos mixtos que caracterizan la migración contemporánea en la región y al mismo tiempo constituyeron acciones erráticas y en contrasentido, la antesala de un viraje sustantivo experimentado por la política migratoria mexicana.
\end{abstract}

Palabras clave: caravanas migrantes; política migratoria; migración forzada.

\begin{abstract}
In 2018 and 2019, migrant caravans took place in order to reach the United States, a migration strategy adopted mainly by Centralamericans, characterized by greater visibility, lower cost and were organized through social networks. Three waves of caravans are identified, related to different institutional measures and bureaucratic-administrative categories. The article exhibits the challenges of the governance of mixed flows that characterize contemporary migration in the region and, at the same time, the measures were erratic and contradictory, the prelude to a substantive turnaround experienced by Mexican migration policy.
\end{abstract}

Keywords: migrant caravans; migration policy; forced migration.

Investigadora visitante en el Center for Latin American \& Latino Studies, American University, Washington DC, US e Investigadora Titular en el Instituto de Investgaciones Jurídicas, UNAM. Ciudad de México, México. E-mail: Igandini@unam.mx. Orcid: https://orcid.org/0000-00021999-4696. 


\section{Introducción}

El término caravanas no resultaba del todo ajeno y novedoso cuando en 2018 y 2019 irrumpieron en la escena de la política migratoria mexicana. Pero las que habíamos conocido anteriormente tenían otros fines: eran expresiones de protesta y de reclamo. Manisfestaciones de familiares de personas migrantes haciéndose ver y escuchar por la violación de derechos a la que estas últimas habían sido sometidas, entre ellas, su propia desaparición. Las caravanas más recientes son otro tipo de manifestación: la de los propios actores de la migración intentando migrar.

La magnificación de estas "nuevas" caravanas y el impacto político regional tuvo origen en la mirada y el señalamiento del presidente estadounidense, Donald Trump, quien públicamente -a través de las redes sociales, como modalidad de hacer política- amenazó con que estas personas no lograrían pasar a los Estados Unidos.

Así, su irrupción en el corredor migratorio Centroamérica-México-Estados Unidos inauguró una nueva era en el manejo de la migración en/de tránsito y la inmigración por el territorio mexicano, caracterizada por la incidencia exterior materializada en los Protocolos de Protección a Migrantes, la militarización del control migratorio y, aunado a lo anterior, a un cambio en la responsabilidad institucional para el manejo o la gobernanza de la migración.

La amenaza del presidente Trump ciertamente se cumplió, en gran medida por las modificaciones de sus propias reglas para el manejo de la inmigración y el asilo, pero también por los cambios de orientación de la política migratoria mexicana.

El presente artículo analiza las medidas con las que el gobierno mexicano respondió institucionalmente a tres oleadas de caravanas migrantes ${ }^{1}$, y muestra que dichas medidas fueron inconsistentes y contradictorias entre sí, culminando en un viraje sustantivo experimentado por la política migratoria mexicana.

La estrategia metodológica que se adopta es de corte cualitativa y se basa en una revisión documental sistemática de pronunciamientos oficiales, acuerdos bilaterales, decretos y modificaciones a la política migratoria. Ello se complementa con un trabajo de campo exhaustivo realizado desde octubre de 2018 a hasta enero de 2020, con visitas frecuentes a la frontera sur (Tapachula) y norte (Tijuana) de México, así como a otros lugares del territorio nacional por

1 Este trabajo culmina con el análisis de la caravana de marzo de 2019. Entre mayo y junio de ese año se producen una serie de cambios (salida del comisionado del Instituto Nacional de Migración, instauración de la Guardia Nacional, amenaza de incremento de los aranceles de parte del presidente Trump, entre otros) que preceden el cambio en la política migratoria. Por lo que aunque en 2020 se organizaron otras caravanas, ellas no se consideran en el análisis de este artículo que analiza la antesala de dicho cambio. 
donde transita o reside población migrante y refugiada en México, como la Ciudad de México, el Estado de México, Hidalgo y la Ciudad de Saltillo².

\section{Las caravanas como estrategia para migrar}

Migrar en caravanas no es algo enteramente novedoso ni para el contexto mundial ni para el regional. Sin embargo, el arribo de estas oleadas o expresiones de caravanas que iniciaron en octubre de 2018 se diferenciaron de sus precedentes porque se organizaron con un único fin que era el de migrar. ¿Por qué ocurre ello si la migración centroamericana en tránsito por México es un flujo de larga data? Los motivos son varios. La agudización de las condiciones de expulsión (Sassen, 2014) en los países de origen condensan varias dimensiones que adoptan distintas expresiones en cada uno de ellos pero que de manera general incluyen: corrupción generalizada en diversos niveles de gobierno, desestabilización del régimen democrático, presencia del crimen organizado y redes de narcotráfico, afectaciones por cambio climático u otros efectos sobre los cultivos, como el identificado en el corredor seco (FAO, 2016). A lo anterior se suman históricas desigualdades sociales que se evidencian en las inserciones precarias e informales en los mercados laborales, generando profundas dificultades económicas. A su vez, contextos restrictivos como los anteriores tienen repercusiones en las economías locales y en las posibilidades de inserción laboral y subsistencia familiar. Por ello, entre otras cosas, resulta cada vez más difícil establecer el límite entre la tradicional -y posiblemente equivocada diferenciación- entre migraciones económicas y forzadas.

Quién va a querer vivir en un país donde no hay trabajo... no hay vida pues... (migrante hondureño entrevistado en Mapastepec, Chiapas, en la tercera oleada de caravanas, marzo 2019)

De lo anterior se desprende que los factores de expulsión -por utilizar un recurso clásico para la explicación de las migraciones- son múltiples y dan lugar a un contexto de desventajas acumuladas que obliga a migrar. En otras palabras, la migración no es "una opción más" dentro de otras estrategias de vida o supervivencia. Es la única que queda para gran parte de esta población. Volviendo a las explicaciones clásicas, los factores de atracción pierden peso.

Pero como se ha anticipado, nada de lo anterior resulta del todo novedoso. En todo caso lo característico de la situación contemporánea del

2 Esta investigación retoma los hallazgos obtenidos del trabajo de campo que realizamos en conjunto con Alethia Fernández de la Reguera y Juan Carlos Narváez Gutiérrez, mi agradecimiento a ambos por compartir y discutir los resultados presentados en este artículo. Agradezco también al Programa de Apoyos para la Superación del Personal Académico (PASPA) de la Universidad Nacional Autónoma de México, que hizo posible mi estancia de investigación en American University, donde escribí este artículo. Mi agradecimiento a Marisol Franco Díaz y a Rocio Madrigal López por la sistematización de datos, elaboración de gráficas y búsqueda bibliográfica y documental. 
desplazamiento centroamericano es el agravamiento de las condiciones en las que acontece. No solo en el origen, sino también en el tránsito y destino. Las personas que se ven forzadas a migrar en general -aunque no en todos los desplazamientos es así- lo hacen en condiciones de gran vulnerabilidad, lo que las coloca como sujetos en riesgo para sufrir otros abusos. Se ha documentado ampliamente la extendida situación de violaciones a derechos a los que se someten quienes se proponen transitar por el territorio mexicano.

Las cifras oficiales de los últimos años (2016-2019) muestran que hubo 3,555 delitos reportados por parte de personas migrantes, dos terceras partes de quienes denunciaron ser víctimas de delitos eran hombres y $20 \%$ niñas, niños o adolescentes (UPM, 2020). Las personas procedentes de Guatemala, Honduras y El Salvador conformaron el grupo originario más afectado en términos de incidencia delictiva, siendo 4 de cada 5 de las víctimas de los delitos reportados. Los delitos más recurrentes que sufren las personas migrantes son el robo, el tráfico ilícito de personas y el secuestro.

En un contexto de amplios riesgos que se manifiestan en todo el proyecto migratorio, la estrategia de las caravanas devino una alternativa sugerente -y también para muchos la única alternativa. Una opción para "escapar de las condiciones de diversas violencias, persecuciones, pobreza y hambre de sus lugares de origen $y$, al mismo tiempo, enfrentar los crecientes riesgos y minimizar los costos que implica el tránsito por el territorio mexicano -secuestros, extorsiones, violaciones, etc. (COLEF, 2018, p. 5).

En otro trabajo (Gandini et al., 2020) hemos identificado tres características que explican -al menos en parte- por qué se optó por migrar en caravanas. La primera de ellas es la búsqueda de mayor visibilidad con el objetivo de obtener mayor protección, en oposición a la estrategia tradicional de invisibilidad y escondite. Los riesgos de atravesar el territorio mexicano se han venido documentando desde hace tiempo y con sistematicidad, al menos en lo que va de este siglo (Ruíz Marrujo, 2001). Se trata de una peligrosidad que ha adquirido diversas modalidades: la presencia de mafias, traficantes de personas, policías, militares, diferentes actores que extorsionan, secuestran, roban y violan a las personas migrantes. A los riesgos anteriores, se suma el de la frustración de la migración, debido al incremento de retenes de control y contención. Entre 2015 y 2019 la autoridad migratoria mexicana ha devuelto a 635,761 personas centroamericanas, tendencia que fue en aumento desde el quinquenio anterior al presentar un incremento de 116\%, pasando de $61 \mathrm{mil}$ eventos en 2010 a 132 mil en 2015 (CONAPO, 2017).

Previo a las caravanas, el tránsito por el territorio mexicano solía realizarse en la noche, por caminos inhóspitos y peligrosos. Quienes emprendían dicho trayecto lo hacían escondiéndose, subiéndose arriba de los vagones del tren. Intentando ser invisibles para no ser vistos por autoridades o bandas 
delincuenciales. Las caravanas modificaron esta estrategia. Las migraciones en caravanas tuvieron lugar a la luz del día, en un grupo consolidado y no disperso, apropiándose de carreteras y caminos a través de filas interminables a la vista. Migrar en grupos para hacerse muy visibles podría funcionar como una estrategia de migración, defensa y protección ante el incremento de la peligrosidad del tránsito. Por ello las caravanas emergieron como una estrategia segura para quien se sumara al contingente pero fundamentalmente para las poblaciones en mayores condiciones de vulnerabilidad y quienes tradicionalmente han sido las más afectadas en el camino: mujeres, niñas y niños (mayormente los que migran sin acompañantes), adultos mayores, personas con discapacidad y personas de la diversidad sexual.

Nunca me hubiera animado a salir, jamás. Pero al ver que la gente se organizaba salí, tomé algunas cosas y me vine. Al fin que no tenía nada que perder. (migrante guatemalteca, ama de casa, viuda, entrevistada en Tapachula, Chiapas, marzo 2019)

La segunda característica que explica el surgimiento de las caravanas es la posibilidad de migrar a un menor costo, evitando la contratación de "coyotes". Con el paso del tiempo, cruzar la frontera de México hacia los Estados Unidos se ha vuelto un hecho más difícil, peligroso y caro. Los cambios en las políticas de inmigración y fronteras del país del norte han sido fundamentales para la formación de diferentes etapas de la migración caracterizadas por patrones distintivos de migración, asentamiento y retorno, con diferentes estatus legales. La era actual se caracteriza por la represión de gran parte de la población migrante irregular, basada en un régimen continuo de detención y deportación masiva (Durand, Massey, 2019), lo que disminuye notablemente las posibilidades de cruzar exitosamente la frontera.

Todo parece indicar que en la actualidad se va clausurando o restringiendo al máximo aquella etapa caracterizada por la industria de la migración (Castles, Miller, 2004) que se instauró en la segunda mitad del siglo pasado, con el paso de una migración circular, relativamente controlada y en parte regular (Programas Braceros) a otra en la que prevaleció la migración irregular, progresivamente más coptada por las redes de tráfico de personas. Si bien los intermediarios o coyotes ${ }^{3}$ han existido desde el nacimiento de este corredor migratorio ${ }^{4}$, con el tiempo sus servicios se fueron sofisticando y conforme se incrementó el riesgo del tránsito por el territorio mexicano y las dificultades del cruce de la frontera sur de los Estados Unidos, los costos de estos servicios también lo hicieron. De acuerdo con los datos recabados por el Proyecto de Migración Mexicana, a finales de la década de los 90 el precio promedio del

\footnotetext{
3 Se denomina coyote a los guías o intermediarios que a través de rutas alternativas evitan controles migratorios, facilitando el trayecto migratorio y la potencial llegada a los Estados Unidos (Spener, 2009).

4 Para Durand y Arias (2005) el término coyote debió haberse usado desde antes de esa fecha.
} 
cruce era de 600 dólares; mientras que en los primeros años de los 2000, se encontraba entre 1,000 y 1,700 dólares. En los últimos años, dicho costo se ha elevado exponencialmente sumando a las dificultades del tránsito, la incorporación en el corredor de personas que provienen de orígenes más diversos y lejanos, incluso de otros continentes. Por ejemplo, de acuerdo a testimonios recabados con personas haitianas, han llegado a pagar 9,000 dólares por persona para llegar a los Estados Unidos. El pago de estos servicios no garantiza el arribo exitoso al país del norte. De manera que, la opción por la invisibilización al transitar por el territorio a modo de hormiga, confundiéndose entre la población nativa, no siempre resultó en una estrategia eficaz y segura para la población centroamericana aunque sí, cada vez más cara.

Finalmente, la tercera característica es la organización del proyecto migratorio, principalmente a través de redes sociales. Paradójicamente se trata de una organización en la espontaneidad. En lugar de la invisibilidad y del coyote, las redes sociales digitales se convirtieron en una herramienta central para la organización de las caravanas y la generación de estrategias de cuidado y protección durante la ruta. Surgieron líderes en el trayecto que fueron "guiando" a los caravaneros de manera relativamente espontánea que, a diferencia de los tradicionales intermediarios o coyotes, no contaban con experiencia, contactos ni conocimiento del camino. El ejemplo de la tercera oleada de caravana formada en Tapachula (detallada más adelante) explica el tipo de dinámica: "La manera de organización fue a través de la creación de grupos de WhatsApp y el reconocimiento de dos líderes: uno de la comunidad cubana y otro de la centroamericana. La información a través de redes o de aplicaciones de celular comenzó a fluir de manera explosiva" (Gandini et al., 2020). Las caravanas ponen en evidencia que la forma de emprender el proyecto migratorio ha cambiado. Recientemente, los estudios sobre migración forzada han comenzado a analizar la importancia de las tecnologías como una de las herramientas más relevantes que utilizan las personas migrantes durante el tránsito migratorio y su integración en los lugares de destino (Castro Cabalceta, 2018; OIM, 2017; Wittebord, 2015; Zijlstra, Van Liempt, 2017). Aunque la tecnología tiende a funcionar como un factor que facilita la migración, en el escenario contemporáneo se observa que se trata de una necesidad básica, particularmente para las personas que buscan protección internacional, que suelen migrar con muy pocos recursos y por caminos que ponen en riesgo su vida (Castelli, 2018).

\section{Entre la migración "económica" y la forzada}

El actual flujo de personas en movilidad -particularmente acentuado en la última década-, no solo de Centroamérica hacia/por México, sino también de otros orígenes y el que distingue al que se moviliza al interior de América 
Latina, se caracteriza por la presencia de flujos mixtos. Una composición de causas complejas y coyunturales que detonan los movimientos migratorios contemporáneos y que se dirigen hacia la mayoría de los países de la región, convirtiéndolos en receptores de personas migrantes. Se trata entonces de movimientos de población complejos que incluyen a refugiados, solicitantes de asilo, migrantes "económicos" y de otros tipos. Se los considera así por la coexistencia de diversas motivaciones en un mismo flujo de personas (OIM, 2019) pero también por la simultaneidad de varios tipos de motivaciones en una misma persona (Posada, 2009).

Las caravanas estaban compuestas por personas amenazadas por grupos criminales, con la pérdida de algún miembro de la familia, despojados de sus tierras -y de sus herramientas de trabajo que en muchos casos debieron vender para subsistir- y cuyos miembros de la familia se encuentran dispersos entre Honduras, México y los Estados Unidos -se trata de una simultaneidad de causas aunque posiblemente enraizadas en una descomposición social, económica y política profunda y estructural- junto a otras personas que, tras numerosos intentos fallidos por llegar al país del norte como una mejor opción de vida, estiman que esta puede ser la oportunidad. Así, aunque con frecuencia se sostiene que quienes migran en caravanas son migrantes forzados, no es tan evidente o simple qué significa ello. En particular, porque se asume a la migración forzada en oposición a la migración voluntaria y a esta última se la equipara con una migración "económica". La especificidad del atributo forzado está dada por la involuntariedad de la acción, es decir, por los motivos o causales que detonaron la migración. Y, como se acaba de ejemplificar, el umbral entre la voluntariedad y lo forzado no es nítido cuando los causales son complejos y se construyen sobre una mixtura de motivaciones que se encuentran profundamente entrelazadas.

En un contexto de esta naturaleza, las categorías se tornan borrosas y los límites poco precisos entre ellas. Una definición general relativamente compartida es la de Susan Gzesh (2008, p. 112), quien sostiene que migración forzada es un "término general que se refiere a los movimientos de refugiados y desplazados internos (desplazados por conflictos) así como a las personas desplazadas por desastres naturales o ambientales, desastres químicos o nucleares, hambrunas o proyectos de desarrollo". Se trata así de una migración "provocada" por violencias estructurales e institucionales que dependen de los Estados involucrados -por acción o por omisión-, como consecuencia de la ausencia del cumplimiento de derechos básicos (Hugo, Bun Kwol, 1990; Castles, 2003; Gzesh, 2008). Así, existe un universo de situaciones promotoras de migración involuntaria cuyas causas no habilitan para el reconocimiento de la condición jurídica de refugiado: no hay una definición legal estándar para este universo de personas en movilidad (Gzesh, 2008). 
No obstante esta limitante, y más allá de la discusión conceptual de cómo pueden enmarcarse este tipo de movimientos de población, el debate de fondo se relaciona con su gobernanza. ¿Cómo ha incrementado la llegada de personas con necesidades de protección internacional en México y de qué manera se ha dado respuesta institucional a ellas?

De acuerdo con los datos reportados por la Comisión de Ayuda al Refugiado (COMAR) presentados en la Gráfica 1, las personas solicitantes de la condición de refugiado han incrementado en casi 5,000 por ciento en la última década, creciendo exponencialmente desde 2015 hasta la actualidad. Concomitantemente a su incremento, también se observa un rezago en las resoluciones, una situación compartida por gran parte de la región latinoamericana, la que en poco tiempo se convirtió en receptora de población migrante y solicitante de la condición de refugiado. En varios países se conjuga la existencia de una legislación relativamente nueva en la materia, junto a la falta de reglamentación de varias leyes domésticas y el uso de otras figuras jurídicas alternativas para responder a flujos específicos, como el caso venezolano, en lugar de la de refugiado (Gandini et al., 2019). En el caso de México, la falta de presupuesto adecuado a las necesidades de COMAR, a lo que también contribuyó el cierre de sus oficinas por varios meses tras el temblor de septiembre de 2017.

\section{Gráfica 1 - Solicitudes de la condición de refugiado recibidas,} resueltas y reconocidas en México, 2000-2019

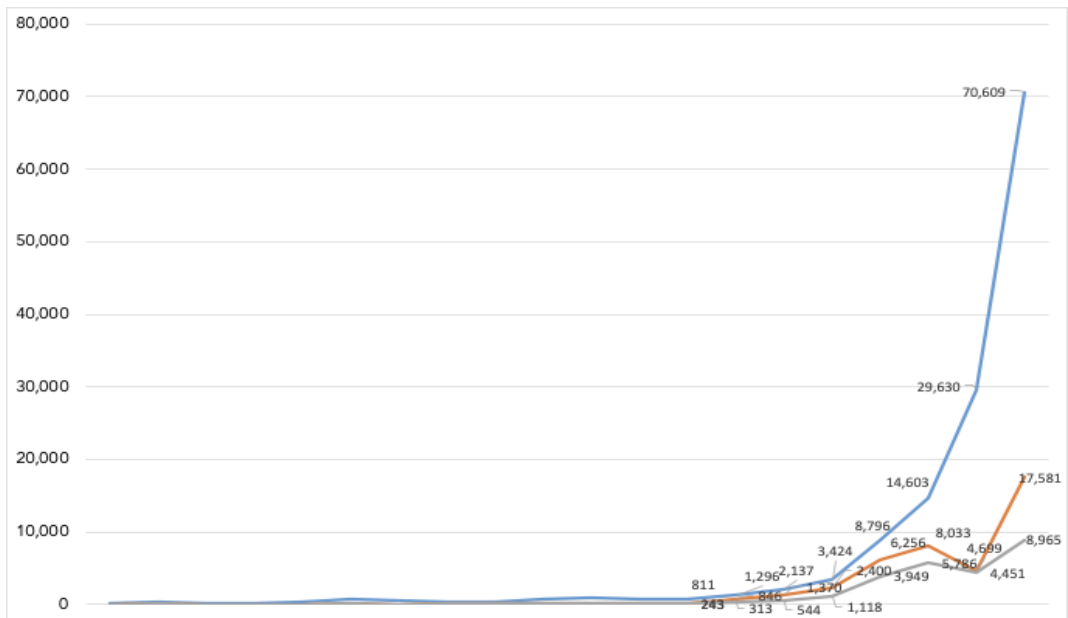

20002001200220032004200520062007200820092010201120122013201420152016201720182019

-Solicitudes recibidas _-Solucitudes resueltas o concluidas _ Solicitudes reconocidas

Fuente: elaboración propia con base en CONAPO (2017), Solicitudes de refugio en México, según dictamen (COMAR), 2000-2016. UPM, COMAR y SEGOB (2018) Boletín Estadístico de Solicitantes de Refugio en México, series 2013-2018. COMAR (2020) Boletín Estadístico Mensual. 
El relativo descenso que se observa en 2020 se debe no solo a que no ha finalizado el año, sino al cierre de fronteras como medidas de mitigación de la pandemia de la COVID-19 (Gráfica 2). Si bien México no adoptó esas disposiciones y siguió recibiendo solicitudes de la condición de refugiado, el cierre de frontera y la suspensión de plazos sí fueron adoptados por Guatemala y otros países de la región, generando restricciones en la movilidad (Vera Espinoza et al., 2020). Sin embargo, vale la pena notar que esta disminución evidencia un comportamiento coyuntural. Si comparamos las cifras del primer semestre del año: entre enero y marzo de 2020 se recibieron 17,203 solicitudes, lo que significa un incremento de $34 \%$ de las recibidas en el mismo periodo del año anterior. Adicionalmente, si bien en el primer semestre del 2020 las solicitudes disminuyeron en $81 \%$ en relación a 2019, si se las compara con las del mismo periodo en 2018, su incremento es de $83 \%$. De lo anterior se desprende que el patrón de migración forzada característico del escenario de movilidad contemporáneo evidenciado en la región persiste a pesar de la momentánea retracción por la pandemia y que, muy posiblemente, retomará su cause en cuanto se reabran las fronteras.

\section{Gráfica 2 - Solicitudes de la condición de refugiado recibidas de enero a agosto, 2018-2020}

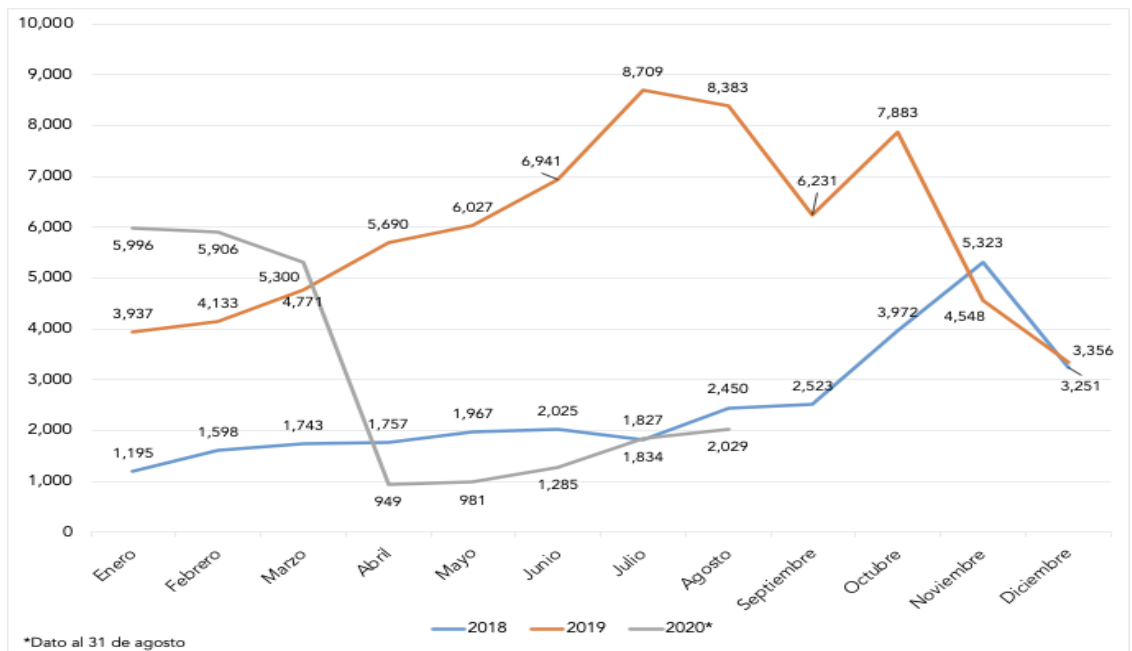

Fuente: elaboración propia con base en CONAPO (2017), Solicitudes de refugio en México, según dictamen (COMAR), 2000-2016. UPM, COMAR y SEGOB (2018) Boletín Estadístico de Solicitantes de Refugio en México, series 2013-2018. COMAR (2020) Boletín Estadístico Mensual.

Las gráficas anteriores constatan, como se anticipó, que más allá de la evidente composición compleja que caracteriza a los causales de las personas que transitan y llegan a México, hay un fuerte componente de migración involuntaria y forzada. Sin embargo, y a pesar del incremento notable de las 
personas solicitantes de la condición de refugiado, no todas ellas entran en la categoría jurídica que les permite otorgar dicha protección. En otras palabras, los datos de solicitantes son indicativos de esta tendencia aunque no exhaustivos de este patrón de migración forzada.

Las interrogantes que surgen de la constatación de la existencia de estos flujos es iqué tipo de respuesta institucional se le ofrece a estas personas? ¿De qué manera se utilizan las categorías jurídicas existentes para la regularización de las personas en movilidad?

Del análisis hasta aquí presentado queda claro que las motivaciones que llevaron a las personas a migrar en caravanas son heterogéneas y que existe una coexistencia de causales. ¿Cuáles fueron las respuestas políticas que se ofrecieron en México para estas personas en movilidad? ¿se las consideró personas en tránsito, inmigrantes, visitantes o personas con necesidades de protección internacional?

\section{Gobernar la movilidad: ¿respuestas diferentes para poblaciones semejantes?}

No existe consenso entre quienes estudiamos el fenómeno sobre cuáles son las caravanas, cuántas son, cuándo comienza esta "era" de caravanas conformadas por personas que se juntan con la finalidad de migrar, etc. Y ello es así, porque en realidad el fenómeno de las caravanas instaura -o consolida- la migración en grupos en donde algunos de ellos han sido más numerosos, visibles e incluso con impactos mediáticos más fuertes. Sin embargo, entre cada uno de estos grandes grupos se ha observado la llegada por goteo de otros compuestos por 50, 100 o 300 personas. "En realidad, se trata de una caravana continua", sostiene una funcionaria de OIM en Tapachula. Son "pequeñas caravanas", que de acuerdo con el relato de autoridades migratorias entrevistadas en el punto de internación de Ciudad Hidalgo (Chiapas), generalmente se ven precedidas por 3 o 4 personas que llegan hasta la frontera "a explorar" cómo está el cruce.

Sin embargo, entre octubre de 2018 y mayo de 2019 identificamos lo que denominamos tres oleadas de caravanas migrantes (Gandini, 2019; Gandini et al., 2020). No significa ello que solo hayan existido tres caravanas, sino que se trata de tres momentos en los que a cada uno de estos grupos de personas migrantes -que han sido los más numerosos- les correspondieron respuestas institucionales diferenciadas. Veamos por qué.

La primera caravana u oleada de caravanas tuvo lugar en octubre de 2018. Su conformación generó un gran interés a nivel nacional e internacional, con impactantes imágenes de miles de personas en el puente fronterizo que une a Ciudad Hidalgo (México) con Tecún Umán (Guatemala). El momento político era inoportuno. México se encontraba en plena transición presidencial. 
Enrique Peña Nieto estaba a días del fin de su mandato para entregar el poder a Andrés Manuel López Obrador. Quizá por lo relativamente acéfalo del poder, a pesar de que la información sobre el arribo de la caravana era conocida, la actitud gubernamental pareció desprevenida.

Se estimó que fueron alrededor de 7,000 personas, con una destacada presencia de mujeres, niñas y niños, personas adultas mayores, familias completas, procedentes fundamentalmente de Honduras (ver Tabla 1). La primera respuesta fue el control migratorio en frontera, al detener el paso de las personas migrantes en el puente, mediante el accionar de fuerzas de seguridad federales. Sin embargo, tras la imposibilidad de contención, se dejó pasar a la caravana derivándola a una improvisada extensión de la estación migratoria Siglo XXI de Tapachula, la Feria Mesoamericana, un espacio sin la infraestructura necesaria para el alojamiento de personas (adultas, niñas y niños, familias). Finalmente, la respuesta que decidió el gobierno fue el inicio de trámites de solicitud de la condición de refugiado para la mayoría, aunque no todas las personas continuaron con el procedimiento. Ello, entre otros motivos, porque en realidad en esta primera oleada era claro que no había intenciones por quienes la conformaban de quedarse en México, sino de seguir camino a los Estados Unidos.

Tabla 1 - Manifestaciones de caravanas y respuestas políticoinstitucionales, octubre 2018 - marzo 2019

\begin{tabular}{|c|c|c|c|c|}
\hline $\begin{array}{l}\text { Oleada de } \\
\text { Caravanas }\end{array}$ & Origen & Características & $\begin{array}{l}\text { Administración } \\
\text { federal }\end{array}$ & Respuestas gubernamentales \\
\hline $\begin{array}{l}\text { Octubre } \\
2018\end{array}$ & $\begin{array}{l}\text { San Pedro } \\
\text { Sula, } \\
\text { Honduras }\end{array}$ & $\begin{array}{l}\text { - Aproximadamente } 7,000 \\
\text { personas } \\
\text { - Procedencia: } \\
\text { fundamentalmente de } \\
\text { Honduras } \\
\text { - Presencia de familias, } \\
\text { personas adultas mayores } \\
\text { - Estancamiento en el } \\
\text { puente internacional }\end{array}$ & $\begin{array}{l}\text { Enrique Peña } \\
\text { Nieto }\end{array}$ & $\begin{array}{l}\text { - Actitud desprevenida } \\
\text { - Primera respuesta: } \\
\text { represión y control en } \\
\text { frontera } \\
\text { - Centros de detención } \\
\text { temporales: Feria } \\
\text { Mesoamericana } \\
\text { - Inicio del procedimiento de } \\
\text { solicitudes de la condición de } \\
\text { refugiado }\end{array}$ \\
\hline Enero 2019 & $\begin{array}{l}\text { San Pedro } \\
\text { Sula, } \\
\text { Honduras }\end{array}$ & $\begin{array}{l}\text { - Aproximadamente } \\
\text { 13,000 personas } \\
\text { - Procedencia: } \\
\text { Centroamérica } \\
\text { - Presencia de familias }\end{array}$ & $\begin{array}{l}\text { Andrés Manuel } \\
\text { López Obrador }\end{array}$ & $\begin{array}{l}\text { - "Anfitriones" } \\
\text { - Organizaciones en el } \\
\text { puente } \\
\text { - Visas humanitarias }(13,270) \\
\text { - Solicitudes de condición de } \\
\text { refugiado }(2,000) \\
\text { - Entrega de tarjetas por el } \\
\text { Comisionado INM y visita Sec. } \\
\text { de Gobernación } \\
\text { - Solidaridad }\end{array}$ \\
\hline
\end{tabular}




\begin{tabular}{|c|c|c|c|c|}
\hline Marzo 2019 & $\begin{array}{l}\text { Tapachula, } \\
\text { México }\end{array}$ & $\begin{array}{l}\text { - Detonante: conflicto } \\
\text { y cierre de oficina de } \\
\text { trámites } \\
\text { - Origen: Tapachula } \\
\text { - 3,000 personas } \\
\text { - Caravana "regular" } \\
\text { - Caravana "irregular" } \\
\text { - Migración por "goteo" } \\
\text { - Procedencia: } \\
\text { Centroamérica y El Caribe } \\
\text { - Presencia de familias } \\
\text { - ¿Efecto llamada? }\end{array}$ & $\begin{array}{l}\text { Andrés Manuel } \\
\text { López Obrador }\end{array}$ & $\begin{array}{l}\text { - Acciones dubitativas y en } \\
\text { contrasentido } \\
\text { - Deportivo de Mapastepec } \\
\text { - Ofrecimiento de Tarjetas de } \\
\text { visitante regional } \\
\text { - Detenciones y } \\
\text { deportaciones } \\
\text { - Centro de detención } \\
\text { temporal: Feria } \\
\text { Mesoamericana } \\
\text { - ¿Hostilidad? }\end{array}$ \\
\hline
\end{tabular}

Fuente: elaboración propia con base en información recolectada con informantes clave y ACNUR (2019).

Con apenas poco más de un mes de instaurado el cambio de administración federal y de signo político, arribó la segunda oleada de caravana, a mediados de enero de 2019, conformada por alrededor de 13,000 personas de origen centroamericano, con una composición más diversa por nacionalidades que la precedente. El consenso es unánime entre distintos actores (sociedad civil, instituciones gubernamentales y agencias internacionales): la respuesta en esta ocasión fue distinta. Todo parecía indicar que con la nueva administración se inauguraba una política de puertas abiertas, tímidamente anunciada en una campaña presidencial donde el tema migratorio no fue central. En un documento publicado por ACNUR (2019, p. 2) se sostenía:

Como resultado del arribo masivo de personas de Centroamérica, el gobierno mexicano empezó a implementar un procedimiento piloto en la frontera de la Ciudad Hidalgo, en el marco de su nueva política migratoria. Bajo esa política, el gobierno se compromete a poner en marcha un régimen migratorio basado en principios de derechos humanos. Aunque diversos detalles de la política faltan ser definidos, se espera que tenga un impacto significativo en los grandes movimientos de personas desde el NCA.

A diferencia de la anterior, a esta caravana se la esperó con anfitriones en el puente que daban la bienvenida a los caravaneros $y$, en lugar de personas abarrotadas, se habían instalado puestos con representantes de agencias gubernamentales (INM, COMAR, DIF), internacionales (ACNUR, OIM), organizaciones de la sociedad civil, representantes de los consulados centroamericanos, etc.

De acuerdo con el testimonio de autoridades de migración, la principal respuesta en esta ocasión fue el otorgamiento generalizado de visas humanitarias, tramitadas en 5 días, las primeras de ellas entregadas en persona por el entonces Comisionado del Instituto Nacional de Migración (INM), Tonatiuh Guillén López, en la frontera sur de México. Desde el gobierno sostuvieron que se iniciaron alrededor de 11,000 visas, a finales de enero de 2019 se entregaron más de 8,600 (ACNUR, 2019). Con estas tarjetas las personas regularizaron su ingreso, obtuvieron libre movilidad por el territorio mexicano y la posibilidad de ingresar al mercado laboral. 
A diferencia de la anterior oleada, en esta solo a una porción pequeña de personas -alrededor de 2,000- se le inició el procedimiento para la solicitud de la condición de refugiado. De acuerdo a los testimonios de personal de ACNUR que labora en Tapachula, la estrategia del otorgamiento expedito de visas humanitarias compitió con el tiempo que tarda COMAR -agencia que como se vio en el apartado anterior se encuentra desbordada por el incremento exponencial de solicitudes y el rezago en su resolución- y desalentó a que personas con necesidades de protección internacional recurrieran a esta figura jurídica.

Finalmente, la tercera caravana no arribó a México porque se gestó dentro del país. A diferencia de las anteriores, este grupo estaba compuesto por una mixtura de situaciones: personas que permanecían desde la primera o la segunda oleada en Tapachula, esperando que avance su trámite de solicitud de la condición de refugiado o que sin haber accedido al trámite -o habiéndolo abandonado- se encontraban en situación irregular, junto a otras de nacionalidades no centroamericanas -fundamentalmente de Cubaque se encontraban "demoradas" o estancadas porque desde el 15 de marzo había cerrado la oficina de trámites migratorios de Tapachula. Este cierre no les permitía gestionar el "permiso de tránsito" o "salvoconducto", tal como lo llama la comunidad cubana. En estricto sentido se trata de un oficio de salida que intima a salir del país en los siguientes 21 días, otorgado generalmente ante el abandono de trámites migratorios. Si bien existente y utilizado con antelación, se volvió una práctica recurrente con el flujo de personas haitianas en 2016 y posteriormente con la población cubana, con la finalidad de transitar con un permiso que otorga regularidad solo por esos días.

Esta caravana se creó con la combinación de dos grupos de personas que en conjunto sumaron cerca de unas 3,000 personas. Uno de ellos de alrededor de 1,500 personas partió el 30 de marzo de 2019 de Tapachula y fue "encauzado" por las propias autoridades federales, encabezadas por Protección Civil, hacia Mapastepec, un municipio de Chiapas a 100 kilómetros de Tapachula -de acuerdo con el relato de varios defensores de derechos humanos de las personas migrantes. De nueva cuenta, en un espacio sin infraestructura e improvisado, fueron alojados en una Unidad Deportiva donde comenzaron a iniciar sus trámites de regularización. Al día siguiente arribó el segundo grupo de alrededor de 1,300 personas a las que ya no se les dio ingreso al deportivo por falta de espacio. El acceso estaba restringido y custodiado por personal de Protección Civil, por lo que se asentaron en un descampado situado enfrente, sin ningún tipo de servicios, ni siquiera árboles para atenuar el extenuante sol. Una funcionaria del INM se refirió a ambos grupos como la caravana regular y la irregular.

Estando en Mapastepec, se escuchaban rumores de que se les otorgarían visas humanitarias a quienes estaban dentro y había mucha incertidumbre 
con quienes estaban en el descampado, a quienes les pidieron en reiteradas ocasiones que hicieran listas y filas, infructuosamente.

Ya desde el 28 de enero, al cierre de la caravana previa, el gobierno anunció que el programa para visas humanitarias había finalizado, y que se acordaría un programa con países centroamericanos para recibir futuras aplicaciones desde los países de origen.

Finalmente, la respuesta en esta tercera ocasión fue el otorgamiento de la tarjeta de visitante regional, ello tras la reforma de los lineamientos y procedimientos en abril previo, extendiendo las nacionalidades a quienes aplica -incluyendo a personas salvadoreñas y hondureñas, originalmente beneficiaba a personas de Guatemala y Belice- y la zona por la que pueden permanecer y transitar, con la modificación se extiende a más entidades federativas del sur de México: Campeche, Chiapas, Tabasco, Quintana Roo y Yucatán.

Así, esta tarjeta de visitante regional habilita el ingreso al país y la permanencia en la zona sur de México por un máximo de siete días, sin permiso para recibir remuneraciones en México. De manera que esta tercera respuesta gubernamental consistió en la regularización bajo una figura de estancia regular "precaria" en la medida en que no permite transitar hacia el norte ni permanecer de forma regular en el país por más de una semana. Es claro que la intención de las caravanas no era realizar una visita a México. Esta respuesta se acompañó de declaraciones de la Secretaria de Gobernación Olga Sánchez Cordero en las que anunció que "ya no se darían visas humanitarias de manera masiva".

La revisión anterior da cuenta de respuestas institucionales diferentes ante un mismo tipo de población, un flujo de personas que inscribimos en lo que se ha reconocido como flujos mixtos con un componente importante de involuntariedad o de migración forzada. Sin embargo, a cada oleada de caravana se respondió no solo con un enfoque de política migratoria diferente, sino con el otorgamiento de categorías burocrático-administrativas distintas. En resumen, a la primera de las oleadas se les inició procedimientos de la condición de refugiado de manera generalizada; a la segunda se otorgaron de manera masiva visas humanitarias y solo a una porción relativamente pequeña se les inició el procedimiento de la condición de refugiado mientras que, en la tercera de las oleadas, las respuestas fueron más dispersas, a algunos se les ofreció visas de visitantes regionales. ¿Se respondió adecuadamente a estos desplazamientos? ¿Qué implicaciones ha tenido ello para el rumbo de la política migratoria mexicana?

\section{Conclusiones}

El arribo de las caravanas, como se dijo, coincidió con el cambio de administración en México que conllevaba un nuevo signo político, tras la 
Ilegada a la presidencia de una nueva fuerza política. El tema migratorio no había sido relevante en la campaña, excepto en uno de los debates de los candidatos en la ciudad de Tijuana. Sin embargo, tras haber ganado la presidencia, Andrés Manuel López Obrador le envió una carta al presidente estadounidense Donald Trump en donde le aseguraba: "el propósito más esencial de mi gobierno será lograr que los mexicanos no tuvieran que migrar por pobreza o violencia. Procuraremos que la migración sea optativa y no necesaria" (López Obrador, 2018). De esta misiva derivan dos concepciones: una errónea y una cierta. La primera es la persistencia de la concepción de México solo como país de origen; la segunda, la imperiosa necesidad de negociar con los Estados Unidos la propia definición de la política migratoria mexicana.

En las últimas décadas, la política migratoria en México fue concebida a partir de su concepción como país expulsor. Por ello, la política o la "no política" -en ocasiones olvidando y en otras exaltando- se centró en la diáspora mexicana en el exterior. Sin embargo, el escenario migratorio no es el de antes: la llegada de personas retornadas a México se incrementó con la crisis de 2008 y el aumento sostenido de las deportaciones (Gandini et al., 2015), la emigración irregular de mexicanos a los Estados Unidos se encuentra en uno de los niveles más bajos desde 1960 (Durand, Massey, 2019), mientras la migración de tránsito en/por México no se detiene (COLEF, 2018). A pesar de ello, no se ha configurado una política migratoria para la inmigración y el tránsito en México.

Bajo la retórica de implementar una migración segura, ordenada y regular, la actual administración ha respondido a las oleadas de caravanas migrantes con acciones dubitativas, erráticas e incluso en contrasentido. Tras una respuesta que reflejaba la instauración de una aparente política de puertas abiertas a la migración en la segunda oleada de caravanas, un efecto llamada (¿no previsto?) propició la persistencia de la llegada de nuevos flujos y, como consecuencia, cambió el rumbo hacia respuestas más restrictivas.

Las diversas respuestas a las caravanas migrantes evidenciaron que no hay una postura clara en la administración mexicana actual acerca de cómo diseñar e implementar políticas para la gobernanza de flujos mixtos. Con las experiencias de las oleadas pareciera advertirse cierto uso discrecional del derecho de asilo y posibles respuestas diferentes para un mismo tipo de población.

Finalmente, las experiencias en la gobernanza de las caravanas migrantes demostró también la correcta advertencia del presidente López Obrador: la importancia de negociar la política migratoria del país con los Estados Unidos. Así es como tras los sucesos previos, el presidente Trump amenazó 
a México en incrementar progresivamente los aranceles comerciales a no ser que se detengan los flujos de personas centroamericanas que transitan por México y llegan hasta la frontera sur estadounidense. Las respuesta de México fue el viraje de la política migratoria con al menos tres sucesos claves que evidencian un cambio histórico en este terreno: a) la intensificación de los Protocolos de Protección a Migrantes, firmados en diciembre de 2018 e implementados desde enero de 2019 con un notable incremento desde mediados de este último año -sumando más de 60 mil participantes hacia agosto de 2020-; b) la militarización del control migratorio, con la creación de la Guardia Nacional, una fuerza en teoría civil pero en la práctica en manos del ejército, que otorgó a las Fuerzas Armadas la responsabilidad en las tareas de seguridad pública; finalmente, c) una reorganización institucional mediante un decreto presidencial (DOF: 19/09/2019), en el que se crea con carácter transitorio (2018-2024) la Comisión Intersecretarial de Atención Integral en Materia Migratoria, dependiente de la Secretaría de Relaciones Exteriores y que "tendrá por objeto fungir como instancia de coordinación de las políticas, programas y acciones que las dependencias, órganos administrativos desconcentrados y entidades de la Administración Pública Federal tienen en materia migratoria". En otras palabras, ello significó el pase de responsabilidad del control migratorio de la Secretaría de Gobernación a la Secretaría de Relaciones Exteriores durante toda la administración actual.

Así se observa el paso de respuestas políticas titubeantes y erráticas al cambio de rumbo en la política migratoria mexicana.

\section{Referencias bibliográficas}

ACNUR. Respuesta Inter-agencial. Movimientos mixtos desde el norte de Centroamérica. Febrero, 2019. Disponible en: <https://www.acnur.org/es-mx/ op/op_fs/5c8c7cbf4/respuesta-interagencial-a-los-movimientos-mixtos-desdeel-norte-de-centroamerica.html>. Acceso en: 13.09.2020.

CASTLES, Stephen; MILLER, Mark J. La era de la migración. Movimientos internacionales de población en el mundo moderno. México: Universidad Autónoma de Zacatecas/Instituto Nacional de Migración/Fundación Colosio/ Miguel Ángel Porrúa, 2004.

CASTLES, Stephen. Towards a Sociology of Forced Migration and Social Transformation. SAGE Journals, v. 7, n. 1, p. 13-34, 2003. Disponible en: < doi. org/10.1177/0038038503037001384>. Acceso en: 13.09.2020.

CASTRO CABALCETA, Daniela. Migrantes conectados. El impacto de la telefonía móvil en la migración. Communicatio, Technologies et Développement, v. 6, 2018. Disponible en: <doi.org/10.4000/ctd.539>. Acceso en: 13.09.2020. 
CASTELLI, Francesco. Drivers of migration: why do people move? Journal of Travel Medicine, v. 25, n. 1, p. 1-7, 2018. Disponible en: <10.1093 / jtm / tay040>. Acceso en: 13.09.2020.

COMAR. Boletín Estadístico Mensual, enero a octubre de 2020. 2020. Acceso en: $<$ https://www.gob.mx/comar/archivo/articulos>.

CONSEJO NACIONAL DE POBLACIÓN (CONAPO). Encuesta sobre Migración en la Frontera Sur de México, 2004-2015 (EMIF SUR). México: Consejo Nacional de Población, 2017.

DURAND, Jorge; ARIAS Patricia. La vida en el norte. Historia e iconografía de la migración México-Estados Unidos. Guadalajara: El Colegio de San Luis y la Universidad de Guadalajara, 2005.

DURAND, Jorge; MASSEY, Douglass. Evolution of the Mexico-U.S. Migration System: Insights from the Mexican Migration Project. The ANNALS of the American Academy of Political and Social Science, v. 684, p. 21-42, July 2019.

EL COLEGIO DE LA FRONTERA NORTE - COLEF. La caravana de migrantes centroamericanos en Tijuana 2018. Diagnóstico y Propuestas de Acción. 2018. Disponible en: <https:/www.colef.mx/wp-content/uploads/2018/12/EL-COLEFReporte-CaravanaMigrante-_-Actualizado.pdf>. Acceso en: 13.09.2020.

FAO (Food and Agriculture Organization). Dry Corridor Central America. Situation report, 2016. 2016. Disponible en: <http:// www.fao.org/emergencies/ resources/documents/resources-detail/en/c/422097/>. Acceso en: 13.09.2020.

FERNÁNDEZ DE LA REGUERA, Alethia ¿Qué sucedió una vez que la caravana migrante salió de Chiapas? Violaciones a los derechos humanos durante los procesos de solicitud de refugio y detención migratoria en la frontera sur. In: GANDINI, Luciana; GONZÁLEZ Nuria (eds.). Caravanas migrantes: las respuestas de México. Ciudad de México: UNAM, 2019, p. 33-42. Disponible en: <https:// archivos.juridicas.unam.mx/www/bjv/libros/12/5804/5.pdf $>$. Acceso en: 13.09.2020.

GANDINI, Luciana. Las "oleadas" de las caravanas migrantes y las cambiantes respuestas gubernamentales. Retos para la política migratoria. In: GANDINI, Luciana; GONZÁLEZ Nuria (eds.). Caravanas migrantes: las respuestas de México. Ciudad de México: Instituto de Investigaciones Jurídicas, Universidad Nacional Autónoma de México, 2019, p. 23-32. Disponible en: < https://archivos. juridicas.unam.mx/www/bjv/libros/12/5804/8.pdf>. Acceso en: 13.09.2020.

GANDINI, Luciana. Deseado u obligado, México es destino. In: Encuentros 2050, n. 38, Ciudad de México: Coordinación de Humanidades, UNAM, 2020.

GANDINI, Luciana; FERNÁNDEZ DE LA REGUERA, Alethia; NARVÁEZ GUTIÉRREZ, Juan Carlos. Caravanas. Ciudad de México: Secretaría de Desarrollo Institucional, Universidad Nacional Autónoma de México, 2020.

GANDINI, Luciana; LOZANO ASCENCIO, Fernando; GASPAR OLVERA, Selene. El retorno en el nuevo escenario de la migración entre México y Estados Unidos. Ciudad de México: Consejo Nacional de Población, 2015. ISBN 978-607-427- 
270-3. Disponible en: <https://www.researchgate.net/publication/316692690_ El_Retorno_en_el_nuevo_escenario_de_la_migracion_entre_Mexico_y_ Estados_Unidos>. Acceso en: 13.09.2020

GANDINI, Luciana; LOZANO ASCENCIO, Fernando; PRIETO, Victoria (coords.). Crisis y migración de población venezolana. Entre la desprotección y la seguridad jurídica en Latinoamérica. Ciudad de México: Secretaría de Desarrollo Institucional, Universidad Nacional Autónoma de México, 2019. Disponible en: <https://www.sdi.unam.mx/docs/libros/SUDIMER-CyMdPV.pdf>. Acceso en: 13.09.2020

GZESH, Susan. Una redefinición de la migracón forzosa con base en los derechos humanos. Migración y Desarrollo, v. 10, p. 97-126, 2008.

HUGO, Graeme; BUN KWOK, Chan. Conceptualizing and defining Refugee and Forced Migrations in Asia. Southeast Asian Journal of Social Science, v. 18, n. 1, p. 19-42, 1990.

LÓPEZ OBRADOR, Andrés Manuel. Carta al presidente Donald Trump. México, 12 de julio, 2018. Disponible en: <https://lopezobrador.org.mx/wp-content/ uploads/2018/07/Carta-firmada.pdf>. Acceso en: 13.09.2020.

ORGANIZACIÓN INTERNACIONAL PARA LAS MIGRACIONES (OIM). World Migration Report 2018. Ginebra: IOM, 2017.

ORGANIZACIÓN INTERNACIONAL PARA LAS MIGRACIONES (OIM). Glossary on Migration. 2019. Disponible en: <https://publications.iom.int/system/files/pdf/ iml_34_glossary.pdf>. Acceso en: 13.09.2020.

POSADA, Paola. Refugiados y desplazados forzados. Categorías de la migración forzada creadas como medidas de contención a las migraciones no deseadas. Estudios Políticos, n. 35, p. 131-152, 2009.

RUIZ MARRUJO, Olivia. Los riesgos de cruzar: La migración centroamericana en la frontera México Guatemala. Frontera Norte, v. 13, n. 25, p. 7-41, 2001. Disponible en: <http://www.scielo.org.mx/scielo.php?script=sci_arttext\&pid $=$ S0187-73722001000100001>. Acceso en: 13.09.2020.

SASSEN, Saskia, Expulsions, Brutality and Complexity in the Global Economy. Cambridge, Massachusetts, Londres: The Belknap Press of Harvard University Press, 2014.

SPENER, David. Mexican Migration to the United States: A Long Twentieth Century of Coyotaje. WorkingPaper, n. 124, San Diego, California: Center for Comparative Immigration Studies of the University of California-San Diego, 2005. Disponible en: <https://ccis.ucsd.edu/_files/wp124.pdf>. Acceso en: 13.09.2020.

SPENER, David. Clandestine crossings. Migrants and coyotes on the Texas-Mexico Border. Estados Unidos: Cornell University Press, 2009.

UNIDAD DE POLÍTICA MIGRATORIA (UPM). Boletín de estadísticas sobre delitos perpetrados en contra de personas migrantes irregulares en su travesía por México, 2020. 2020. México: Secretaría de Gobernación, 2020. 
UPM, COMAR y SEGOB. Boletín Estadístico de Solicitantes de Refugio en México, series 2013-2018. 2018. Disponible en: <https://www.gob.mx/comar/articulos/ boletin-estadistico-de-solicitantes-de-refugio-en-mexico-182244?idiom=es $>$.

VERA, Marcia; ZAPATA, Gisela P.; GANDINI, Luciana. Movilidad en la inmovilidad: migrantes atrapados bajo la Covid-19 en América Latina. Open Democracy, 26 de mayo, 2020. Disponible en: <https:/www.opendemocracy.net/es/ democraciaabierta-es/movilidad-en-la-inmovilidad-migrantes-atrapados-bajola-covid-19-en-am\%C3\%A9rica-latina/> . Acceso en: 13.09.2020

WITTEBORD, Saskia. Becoming (Im) Perceptible: Forced Migrants and Virtual Space. Journal of Refugee Studies, 2015. Disponible en: <https://doi.org/10.1093/jrs/ feu036>. Acceso en: 13.09.2020.

ZIJLSTRA, Judith; VAN LIEMPT, Ilse. Smart(phone) travelling: understanding the use and impact of mobile technology on irregular migration journeys. International Journal Migration and Border Studies, v. 3, n. 2, 2017. 